\title{
Rule of Law and the Environmental Kuznets Curve: Evidence for Carbon Emissions
}

\author{
Concetta Castiglione, Davide Infante \\ and Janna Smirnova
}

TEP Working Paper No. 0111

January 2011

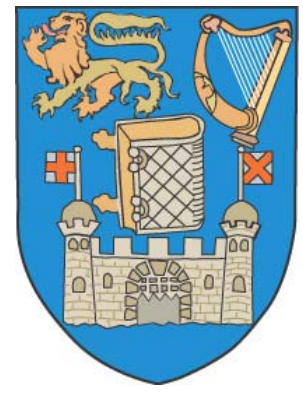

Trinity Economics Papers

Department of Economics

Trinity College Dublin 
Rule of law and the Environmental Kuznets Curve: evidence for carbon emissions

\author{
Concetta Castiglione ${ }^{1}$, Davide Infante ${ }^{2}$ and Janna Smirnova ${ }^{3}$ \\ ${ }^{1}$ Trinity College Dublin, Department of Economics \\ ${ }^{2,3}$ University of Calabria, Department of Economics and Statistics
}

\begin{abstract}
In response to recently growing literature investigating the relationship between environment and institutions, this study investigates how rule of law influences the level of income at the turning point of the Environmental Kuznets Curve (EKC). Using an alternative specification of EKC that avoids nonlinear transformation of potentially nonstationary regressors, investigated by Bradford et al. (2005) and Leitão (2010), we find the evidence for the EKC in European countries for carbon emissions. Our results find a negative relationship between pollution and rule of law, demonstrating that when rule of law is strong, the turning point of the EKC occurs at a lower level of income per capita, thus, decreasing emissions. In terms of policy implication, our study suggests that institutional reinforcement should deserve close attention in designing and enforcing policies that limit environmental degradation.
\end{abstract}

Keywords: Environmental Kuznets Curve, Rule of law, Panel data, Turning point

JEL Classification: O43, O44, Q53, Q58

\title{
1. Introduction
}

A constantly increasing body of literature is providing evidence regarding importance of institutions in environmental issues (Panayotou 1997, Torras and Boyce 1998, López and Mitra 2000, Dasgupta et al. 2001, Damania et al. 2003, Dinda 2004, Cole 2007 and others). As argued, the institutional approach offers important implications for environmental studies and analytical frameworks for their study (Paavola and Adger 2005). This is due to two interdependent reasons. First of all, environmental issues are rarely managed without state intervention and, therefore, must comply with regulation. At the same time, state regulation strongly depends on the strength of the institutional context of a society. This implies that environmental governance involves the establishment and enforcement of institutions.

Although the number of studies on the environment-institutions relationship is constantly increasing, studies analyzing the impact of institutions on environment issues is far from exhaustive. In one of the most frequently analysed concepts such as Environmental Kuznets Curve (EKC), institutions also start playing an important role.

The EKC, named after Kuznets (1955), emerged within the environmental context in the early 1990s with a seminal paper, stating that environmental degradation first increases and then falls beyond a certain level of per capita income (turning point). A large body of empirical literature analysing the existence and the shape of the EKC, 
apart from the classical relationship between polluters and income, considers among the regressors other variables, which influence environmental quality, such as macroeconomics conditions, industrial development, resources availability etc. Institutions are also often incorporated in such schemes (Bhattarai and Hammig 2001, Yandle 2004, Cole 2007, Culas 2007). However, there is very scarce empirical evidence showing the influence of institutions on the position of the turning point of EKC (for the discussion see Yandle 2004). To our knowledge, studies in this field mostly concentrate upon the role of weak institutions, such as corruption mechanism (López and Mitra 2000, Cole 2007, Leitão 2010). In this paper, we propose to analyse the impact of institutional stringency, i.e. of the rule of law on the turning point of the EKC.

Rule of law should be considered one of the institutions that plays a crucial role in environmental issues, given that environmental controls almost always depend on regulation and are rarely adopted without regulation stimulus. The EKC provides an ideal context for demonstrating the importance of the rule of law on the position of the turning point whereby a more rigorous reinforcement of rule of law leads to a lower level of income at turning point, thus decreasing the level of pollution.

To test this hypothesis we apply the parametric specification of the EKC introduced by Bradford et al. (2005). This approach avoids nonlinear transformations of potentially nonstationary variables, such as quadratic or cubic forms of income, often utilised to capture the inverse U-shape which may constitute a robustness problem for panel data. Moreover, following the approaches presented by Welsch (2004) and Cole (2007), we incorporate and identify both the direct effects of the rule of law on pollution and its indirect effects on pollution through per capita income. The data we utilise for the analysis include a panel of carbon emissions for 28 European countries from 1996 to 2008.

The paper is organised as follows. Section two examines the literature on the relationship between environment and institutions within the EKC context. Section three outlines the applied methodology. Section four describes the data utilised, section five presents the results while section six concludes.

\section{Backgrounds for EKC and institutions}

The degree of institutional development is demonstrated to have a significant impact on environmental issues (Panayotou 1997). The literature examining the links between institutions and environmental quality within the EKC context is quite well developed. At the theoretical level, Brock and Taylor (2003) and Yandle (2004) have demonstrated the incidence of the institutions on the income-pollution paths and on the turning point of the EKC and have shown the importance of institutional enforcement on pollution abatement.

At empirical level, some institutions or their sets are taken into consideration when investigating the existence and the shape of the EKC. Corruption is one of the most analysed institutional issues that expands the classical form of the EKC. López and Mitra (2000) and Leitão (2010) have demonstrated that in the presence of corruption, the turning point occurs at a higher level of income per capita. Institutions such as political liberties and civil rights incorporated among regressors weaken the income effect in the EKC hypothesis (Torras and Boyce 1998, Bhattrai and Hammig 2001). Democracy is found to contribute significantly to flatten the $\mathrm{EKC}$ for different polluters 
(Torras and Boyce 1998, Frankel and Rose 2002). Secure property rights are also important in achieving an earlier turning point on the EKC (Culas 2007). The above studies therefore indicate that enforced institutions can reduce environmental degradation at lower per capita income and accelerate improvements at higher income levels, reducing environmental price of growth (Panayotou 1997).

Although the rule of law is one of the important institutions for environmental issues, it has not been widely considered in the empirical literature of the field with only a few studies on the EKC incorporating the rule of law. Panayotou (1997) utilises a composed index of institutions that includes rule of law, proposed by Knack and Keefer (1995), demonstrating that a better institutional enforcement contributes to flatten the EKC for sulflur dioxide emissions. Bhattarai and Hammig (2001) utilized the Freedom House civil liberty index incorporating the rule of law and demonstrated that institutional improvements significantly reduce the degree of deforestation.

We argue that further discussions on the role of rule of law in environmental issues is required. In fact, in cases where the market has to comply with state regulations, such as in the case of pollution abatement, favourable economic institutions in the form of rule of law represent the background for functional policies. Our model investigates the influence of rule of law on the position of the turning point of the EKC and considers the direct and indirect effects that rule of law plays on carbon emissions, one of the most important greenhouse gases. Following Welsch (2004) and Cole (2007), we analyse the linkages between rule of law and carbon emissions, that constitutes a direct effect of rule of law on environment while the indirect effect through which rule of law influences pollution is its impact on income. In fact, extended empirical literature find that stronger rule of law enhances economic growth (Knack and Keefer 1995, Dollar and Kraay 2000, Butkiewicz and Yanikkaya 2006 and others). By influencing income per capita, rule of law is expected to influence pollution levels and, thus, the position of the EKC.

Here, we investigated the effect of rule of law on carbon emissions, one of the primary polluting greenhouse gases. Around $80 \%$ of the world's energy demand is met by fossil fuels (Energy Information Administration, 2004), leading to the substantial release of carbon emissions into atmosphere. A large strand of empirical literature concentrates on carbon emissions and on their abatement. Many studies confirm the existence of the EKC for this polluter in various countries (Selden and Song 1994, Hil and Magnani 2002, Cole 2003, Friedl and Getzner 2003, Galeoti et al. 2006, MüllerFürstenberger and Wagner 2007, Dutt 2008, Atici 2009, Lipford and Yandle 2010). While Most of these studies have found the existence of an inverse U-shape curve for carbon emissions, some have found that the EKC may have an $\mathrm{N}$-shape form (Cole 2003, Friedl and Getzner 2003) or an inverted U-shape with rising tails (Lipford and Yandle 2010) which can be due to Golkany's (1999) effect where these forms of the EKC arise due to unsustainable environmental protection costs.

In estimating the existence and the shape of the EKC, most studies utilise different functional forms, such as linear, squared, and cubed equations. Although very diffuse, these approaches is criticised in the literature (Stern 2004, Bradford et al. 2005, Wagner 2005, Müller-Fürstenberger and Wagner 2007) due to the problems arising in presence of nonstationary variables, such as, for example, income per capita. The fact is that, in introducing a non-linear trasformation of nonstationary processes, it is not always appropriate to utilise a linear unit root estimation (Stern 2004). The asymptotic theory of nonlinearly transformed integrated variables, in fact, has not been yet developed for 
panel data (Bradford et al. 2005). Another problem that derives from unit root nonstationarity is that of the presence of cross-sectional dependence. To avoid these problems, an alternative parametric specification of the EKC was introduced by Bradford et al. (2005). Following this approach a change of pollution is introduced as a function of the growth rate and the distance of income to the turning point. As an extension to this approach Leitão (2010) introduces corruption and investigates the role that it plays on income and pollution. Following this approach, we analyse the incidence of the rule of law on the turning point of the EKC for carbon emissions.

This study thus aims to evaluate whether EU countries have the EKC for carbon emissions and if so, determine the impact of the rule of law on the turning point beyond which economic growth improves environmental quality. In addition, we also investigate the impact of other factors, such as manufacturing concentration, international trade and other country-specific factors on carbon emission levels. The main contribution of this paper is to demonstrate the importance of rule of law in limiting environmental degradation by considering the direct and indirect effects that this institution plays on pollution. The key feature differentiating our study is also the incorporation of rule of law into the $\mathrm{EKC}$ by utilising the alternative parametric approach described by Bradford et al. (2005). Finally, our findings highlight the importance of institutional enforcement for environmental preservation and contribute to design sustainable development policies in European countries.

\section{Methodology}

In order to avoid the use of nonlinear transformation of nonstationary regressors, such as GDP per capita, in panel data estimation, we refer to an alternative specification of the EKC proposed by Bradford et al. (2005). This approach consists of representing the EKC based on the relationship between the rate of change of pollution, per capita GDP, and the growth rate of per capita GDP at a given point in time:

$$
\frac{\partial P_{t}}{\partial t}=\alpha\left(y-y^{*}\right) g
$$

Therefore, the change of pollution $(P)$ is a function of the growth rate of GDP $(g)$ and of the distance from the turning point of $\operatorname{EKC~}\left(y^{*}\right)$. In the case where the coefficient $\alpha$ is negative, and $g$ is positive, $P$ increases until $y^{*}$ is reached and decreases after the turning point. A negative sign of $\alpha$ thus indicates the presence of the inverse U-shaped relationship between pollution and GDP per capita. Country subscripts $i$ are omitted for the sake of simplicity.

Given that our scope is to check for the impact of the rule of law on the turning point of the EKC, we suppose that the turning point $y^{*}$ is a function of the degree of rule of law. Following Leitão (2010), rule of law is introduced in equation (1) as follows:

$$
y^{*}=\delta_{1}+\delta_{2} R o l
$$

where Rol is the average degree of rule of law over a sample period for each country. When $\delta_{2}<0$, higher degree of rule of law implies lower level of GDP per capita in the 
turning point $y^{*}$.

The equation to estimate is obtained by integrating with respect to time, the combination of equations (1) and (2) while keeping income, average growth rate and average degree of rule of law as constants:

$$
P_{t}=\mu+\alpha\left(y-\left(\delta_{1}+\delta_{2} R o l\right)\right) g t
$$

where $\mu$ is an integration constant.

For empirical applications, equation (3) is written in the following reduced form:

$$
\ln P_{i t}=\mu_{i}+\beta_{0}\left(y_{i} g_{i} t\right)+\beta_{1}\left(g_{i} t\right)+\beta_{2}\left(\operatorname{Rol}_{i} g_{i} t\right)+\beta_{3} Z_{i t}+\varepsilon_{i t}
$$

where the countries are indexed by $i$ and time by $t . P_{i t}$ is the carbon emissions per capita, $y_{i}$ is the average real per capita GDP, $g_{i}$ is the average real per capita GDP growth and $\mathrm{Rol}_{i}$ is the average of the degree of the rule of law, all measured over the sample period. $Z_{i t}$ refers to a set of additional variables that has impact on carbon emissions, such as energy consumption, manufacturing share in GDP, population density and international trade.

We suppose that $R l_{i}$ not only influences pollution level and the turning point of the $\mathrm{EKC}$, but also a country's income, which is a component of the $\mathrm{EKC}$ regression. In order to capture the indirect effect that rule of law has on carbon emissions, the first step is to estimate the following growth equation:

$$
Y_{i t}=\lambda_{i}+\tau_{i}+\gamma_{1} R_{i t}+\gamma_{2} X_{i t}+\varepsilon_{i t}
$$

where real GDP per capita $\left(Y_{i t}\right)$ is expressed as a function of the rule of law $\left(R_{i t}\right)$ and $\left(X_{i t}\right)$ is a matrix of other regressors that affect income. According to the literature regarding economic growth, this matrix consists of typical variables such as capital stock per worker, level of education and share of trade in GDP. $\lambda_{i}$ and $\tau_{i}$ correspond respectively to unobserved country-specific effects and year-specific effects. From the equation (5) we evaluate $\gamma_{1}$ to obtain the impact the rule of law has on real GDP per capita.

Average values $y_{i}$ and $g_{i}$ are obtained from equation 5 by using interpolation techniques after having calculated the fitted values of $Y_{i t}$. Following Bradford et al. (2005), we compute the average value of per capita GDP of the first (denote by $Y_{i}^{1}$ ) and the latest (denote by $Y_{i}^{2}$ ) four year period of the total of GDP series for each country. The average growth rate $g_{i}$ is obtained from the following equation:

$$
Y_{i}^{2}=Y_{i}^{1} \exp \left(10 g_{i}\right)
$$

while $y_{i}$ is computed as:

$$
y_{i}=Y_{i}^{1} \exp \left(5 g_{i}\right)
$$

i.e. $y_{i}$ and $g_{i}$ are interpolated values at the sample mid-point.

In estimating equation (4) we utilise the above interpolated values and a simple average of the degree of rule of law $\left(R_{o l}\right)$ over the sample period. In doing so, we 
address the direct and indirect effects that rule of law plays on the level of carbon emissions and on the turning point of the EKC.

\section{Data and Descriptive Statistics}

Data used in this analysis was obtained from a panel of 28 countries from 1996 to 2008 for a total of 392 observations. To estimate Equation 5 we divide countries into three groups. The First group $(G l)$ includes European countries with strong industrial and service sectors, such as Austria, Belgium, Denmark, Finland, France, Germany, Luxemburg, Netherlands, Norway, Sweden and United Kingdom. Countries with substantial part of the regions that present retard in industrial and service sectors development constitute the second group (G2): Cyprus, Greece, Ireland, Italy, Malta, Portugal and Spain. Former socialist countries with restructuring industrial sectors and developing service sectors belong to the third group (G3): Bulgaria, Czech Republic, Estonia, Hungary, Latvia, Lithuania, Poland, Romania, Slovakia and Slovenia. Such a division is necessary to capture how diversified production and economic conditions affect income and environment.

Carbon emissions are measured through total tons of carbon monoxide (CO) gas released by industries and households. The data is taken from Eurostat (2010). The index of rule of law is provided by Kaufman (2010) and is measured in units ranging from -2.5 to 2.5 , with higher values corresponding to better quality of this institution. Data on rule of law is available since 1996, which was considered the first year of our study. Other regressors utilised to estimate the EKC, such as electricity production from coal, share of manufacturing in GDP, population density and share of exports and imports in GDP were taken from World Development Indicators (World Bank, 2010). These explanatory variables were chosen on the basis of existing literature in this field (Dinda 2004, Bradford 2005, Atici 2010 and Leitão 2010). These indicators are frequently utilised for evaluating economic activity that leads to production of carbon emissions. In fact, electricity production and manufacturing have a direct impact on greenhouse gases (Dinda 2004, Leitão 2010). While international trade and population density, which may indirectly influence emission intensity may have both positive and negative effects on pollution. If import prevails over export it may decrease emissions, since the production processes take place overseas. Population density may also have both effects on pollution (Bhattarai and Hamming, 2001). Negative impact, in fact, is noted because densely populated countries use less energy for transportation per capita than do more sparsely populated countries (EIA 2010). Positive effects on pollution, can, on the other hand, be due to more intense consumption of household and production energy.

In estimating equation 5 that addresses the indirect effect of rule of law through income level and income growth, we utilised data on real per capita GDP, capital per worker, education and share of export and import in GDP, taken from World Development Indicators (World Bank, 2010). The analysis is based on an unbalanced panel data, given that some observations are not available. Description sources of data of the used variables are summarised in Table 1, while in Table 2 sample summary statistics are presented.

Estimation results of equation 5 are summarised in Table 3. A possible bias resulting from endogeneity between rule of law and income per capita emerged from 
the estimation. To address this problem, rule of law was instrumented by (i) the fraction of population that speaks English as a mother tongue; (ii) the fraction of population that speaks one of the five primary Western European languages, including English as a mother tongue and (iii) the overall index of economic freedom (see Table 1). First stage regression indicates the validity of the instrumental variables we chose. The validity of the first two instruments was also confirmed by Hall and Jones (1999), Cole (2007) and Leitão (2010).

It is important to note that, in estimating panel data, one should consider the difference between fixed and random effect models (Cameron and Trivedi, 2009). The effect of country-specific characteristics, potentially correlated with the dependent variable, can be explored by estimating both the fixed and the random effects models. If country-specific characteristics are correlated with the explanatory variables, the fixed effects should be preferred to random effects. Otherwise, random effects estimation is consistent and efficient. Equation 5 is estimated as the random effects model, given that introduced time invariant instruments prevent the potential correlation between country-specific effects and the explanatory variables.

In estimating equation 4 (Table 5) it is very likely that the country's unobservable characteristics can be correlated with income. This suggests that fixed effects estimation could be more appropriate than random effects estimation. In our case, given the significance of Hausman test statistics, the random effects model is rejected in favour of the fixed effects model. For this reason, for equation 4, we only report the results from the fixed effects estimation (Table 5).

\section{Results and Discussion}

Estimation results of equation 5 were used to obtain interpolated average values of per capita income and growth rate in order to calculate fitted values for the estimation of the EKC (equation 4). Equation 5 is estimated (Table 3) for the three groups of countries $(G 1, G 2, G 3)$ introduced in section 4. Given the presence of fitted values and following Leitão (2010), we do not express variables in naturals logarithms. In all estimations, rule of law is instrumented using 2SLS.

Equation 5 was also estimated for the full sample. However, this approach did not prove to be an efficient tool for the EKC estimation, given that countries-specific institutional, and therefore, environmental characteristics could not be captured.

As suspected, rule of law $\left(R_{i t}\right)$ does not have the same impact on income across the three groups of countries. In $G l$ group the variable is significant and has a positive expected sign. In $G 2$ group the variable has negative sign, being statistically significant. Nonetheless the presence of unexpected sign, we can attempt to explain this finding by considering the fact that during the analysed period, most of these $G 2$ economies have worsened their institutional performance, thus drastically decreasing the rule of law index while increasing income per capita. In fact, the average rule of law index in $G 2$ is 1.1 while in $G 1$ is 1.7 . Probably, in $G 2$ countries the negative effect of the worsening institutional context on growth was strongly counterbalanced by other more important economic factors. As expected, former-transition countries (G3) that present the lower average value of rule of law index $(0.57)$ do not show statistically significant relationship between income and rule of law. 
Capital per worker affects income positively and significantly. The variable $E d u$ is also positive and significant in all countries except for $G 2$. The share of exports and imports in GDP (XIMsh) is also influencing income positively and significantly. These results are robust across all the alternative specifications.

The relevance of instruments is tested at the first step of regression (Table 4). All instruments are significant at least in one regression. Variable Engfrac - fraction of a country's population that speaks English as a mother tongue is not present in the regression for former-transition countries, given that it is invariant over the sample period. Moreover, the Wald test is significant in all estimations. Other variables, such as distance from the equator, dummy for legal origin of each country and others were added as instruments in the regression but these instruments did not prove to be valid and the obtained results did not change.

Table 5 provides the estimation results for equation 4. A basic regression of the EKC that involves ygt, gt and Rolgt (see section 3) was first estimated with no additional explanatory variables $(\mathrm{Z})$. Models from $(\mathrm{Yb})$ to $(\mathrm{Ye})$ add the percentage of electricity production from coal sources $(C O A L)$, the share of manufacturing output in GDP (MANUsh), the country's population density (POPdens) and the share of export plus imports in the country's GDP (XIMsh). The Variables ygt, gt and Rolgt are significant with expected signs in all specifications of the model. The negative coefficient of $y g t$ indicates the presence of the EKC for carbon monoxide emissions in European countries. The negative sign on Rolgt demonstrates the existence of the inverse relationship between the strength of the rule of law and the intensity of pollution. Moreover, the estimated value of $\delta_{2}$ is negative and statistically significant, indicating, in accordance to our theoretical model, that when rule of law is strong, the turning point of the EKC occurs at a lower level of income per capita.

Surprisingly, the variable of Energy was found to be not significant in determining carbon monoxide emissions. On the contrary, manufacturing was found, as expected, to be a positive and significant determinant of carbon monoxide emission in Europe. In confirmation that European countries mostly import manufacturing goods from abroad, while exporting services, we found a negative and significant sign of the export and import variable. As for a country's population density, this variable was significant with a negative sign, confirming the EIA (2010) hypothesis that sparsely populated countries have lower emissions since they use less energy for transportation per capita.

\section{Conclusions}

In the light of the previous literature on institutional-environmental relationship, we consider the EKC under the lents of the rule of law institution. Our work adds to the previous institutional-environmental literature that investigates on the position of the turning point of the EKC (Yandle et al. 2004 and Leitão 2010) the analysis of the influence of rule of law on the income level at the turning point.

Data covering a panel of 28 European countries for the period between 1996-2008 were utilised to estimate a model examining the linkages between income per capita, carbon emissions and the state of rule of law. We find the existence of the EKC for carbon monoxide by applying the Bradford et al. (2005) approach that builds the curve avoiding nonlinear transformation of possibly nonstationary regressors, such as income per capita and thus avoids potential problems of robustness. The introduction of rule of 
law into the model follows the approach presented by Leitão (2010). Our analysis can, therefore, be seen as a robustness test for results presented by both Bradford et al. (2005) and Leitão (2010).

We find that rule of law is negatively correlated with pollution and contributes to the achievement of an earlier turning point on the EKC, so that stronger rule of law corresponds to lower threshold income level. Our findings confirm the proposition advanced by Yandle et al. (2004) who argues that every point of the EKC is associated with specific institutional framework and reinforcement of institutions facilitates the race to the top of the curve.

Moreover, we investigate the influence of rule of law on income level and on its growth, addressing the indirect effect of rule of law on carbon emissions. Our results confirm that the reinforcement of institutions plays a crucial role for the control of environmental quality and has important implications for limiting environmental degradation.

Our analysis suggests that rule of law enforcement promotes environmental protection and reduces the level of per capita income beyond which pollution declines. Turning to policy implications, the empirical model provides strong evidence that institutional factors deserve close attention in designing environmental policies.

\section{References}

Atici, C. 2009. "Carbon emissions in Central and Eastern Europe: environmental Kuznets curve and implications for sustainable development." Sustainable Development, 17, no. 3: 155-160.

Bhattarai, M., and Hammig, M. 2001. "Institutions and the Environmental Kuznets Curve for deforestation: a cross-country analysis for Latin America, Africa, and Asia." World Development, 29, no 6: 995-1010.

Bradford, D.F., Fender, R.A., Shore, S.H., and Wagner, M. 2005. "The Environmental Kuznets Curve: Exploring a Fresh Specification." Contributions to Economic Analysis \& Policy, 4, no. 1.

Brock, W.A., and Taylor, M.S. 2003. "The Kingdergarten Rule of Sustainable Growth." Working Paper no. 9597, National Bureau Of Economic Research.

Butkiewicz, J.L. and Yanikkaya, H. 2006. "Institutional quality and economic growth: Maintenance of the rule of law or democratic institutions, or both?" Economic Modelling 23, no 4: 648-661.

Cameron, A.C., and Trivedi, P.K. 2009. Microeconometrics Using Stata. College Station, Texas.

Cole, M.A. 2003. "Development, trade, and the environment: how robust is the Environmental Kuznets Curve?" Environment and Development Economics 8, no 4: 557-580.

Cole, M.A. 2007. "Corruption, income and the environment: an empirical analysis." Ecological Economics 62, no 3-4: 637-647.

Culas R.J. 2007. "Deforestation and the environmental Kuznets curve: an institutional perspective." Ecological Economics 61, no 2: 429-437.

Damania, R., Fredriksson, P.G. and List, J.A. 2003. "Trade liberalization, corruption, and environmental policy formation: theory and evidence." Journal of Environmental Economics and Management 46, no 3: 490-512.

Dasgupta, S., Mody, A., Roy, S., and Wheeler, D. 2001. "Environmental regulation and 
development: a cross-country empirical analysis." Oxford Development Studies 29, no 2: $173-187$.

Dinda S. 2004. "Environmental Kuznets curve hypothesis: A survey." Ecological Economics 49, no 4: 431-455.

Dollar, D., and Kraay, A. 2000). "Property Rights, Political Rights, and the Development of Poor Countries in the Post-Colonial Period." World Bank Working Papers.

Dutt, K. 2008. "Governance, institutions and the environmental-income relationship: a cross-country study" Environmental, Development and Sustainability, 11, no 4: 705-723.

Energy Information Administration, 2004. International Energy Annual 2002.

Energy Information Administration, 2010. International Energy Outlook 2010, http://www.eia.doe.gov/oiaf/ieo/emissions.html

Eurostat, 2010. Eurostat Statistics, available on line

Frankel, J.A., and Rose, A.K. 2002. "Is Trade Good Or Bad For The Environment? Sorting Out The Causality." Working Paper 9201, National Bureau Of Economic Research.

Friedl, B. and Getzner, M. 2003. "Determinants of CO2 emissions in a small open economy." Ecological Economics 45 no 1: 133-148.

Galeotti, M., Lanza, A. and Pauli, F. 2006. "Reassessing the environmental Kuznets curve for $\mathrm{CO} 2$ emissions: A robustness exercise." Ecological Economics 57, no 1: $152-163$.

Goklany, I.M. 1999. Clearing the Air: The Real Story of the War on Air Pollution, Washington: CATO Institute.

Grossman, G.M., and Krueger, A.B. 1991. "Environmental impacts of a North American Free Trade Agreement." Working Paper 3914, National Bureau Of Economic Research.

Hall, R.E. and Jones, C.I. 1999. "Why do some countries produce so much more output per worker than others?" The Quarterly Journal of Economics 114, no 1: 83-116.

Hil, R.J. and Magnani, E. 2002. "An exploration of the conceptual and empirical basis of the Environmental Kuznets Curve." Australian Economic Papers 41, no 2: 239254.

Kaufmann, D., Kraay, A., and Mastruzzi, M. 2010. "The Worldwide Governance Indicators : A Summary of Methodology, Data and Analytical Issues." World Bank Policy Research.

Knack, S., and Keefer, P. 1995. "Institutions and economic performance: cross-country tests using alternative institutional measures." Economics and Politics 7, no 3: 207227.

Kuznets, S. 1955. "Economic Growth and Income Inequality." American Economic Review 45, no 1: $1-28$.

Leitão, A. 2010. "Corruption and the environmental Kuznets Curve: Empirical evidence for sulfur." Ecological Economics 69, no 11: 2191-2201.

Lipford, J.W., and Yandle, B. 2010. "Environmental Kutnets curves, carbon emissions, and public choice." Environmental and Development Economics 15, no 4: 417-438.

López, R., and Mitra, S. 2000. "Corruption, pollution, and the Kuznets environment curve." Journal of Environmental Economics and Management 40, no 2: 137-150.

Müller-Fürstenbergera, G. and Wagnerb, M. 2007. "Exploring the environmental Kuznets hypothesis: Theoretical and econometric problems." Ecological 
Economics, 62, no 3-4: 648-660.

Paavola J. and Adger, W.N. 2005. "Institutional ecological economics." Ecological Economics, 53, no 3: 353-368.

Panayotou, T. 1997. "Demystifying the Environmental Kuznets Curve: turning a black box into a policy tool." Environment and Development Economics 2, no 4: 465484.

Selden, T.M., and Song, D. 1994. "Environmental quality and development: is there a Kuznets Curve for air pollution emissions?" Journal of Environmental Economics and Management 27, no 2: 147-162.

Stern, D.I. 2004. "The environmental Kuznets curve.", in: Cleveland, C.J. (ed.) Encyclopedia of Energy, Academic Press, San Diego CA, 517-525.

Torras, M., and Boyce, J.K. 1998. "Income, inequality and pollution: reassessment of the Environmental Kuznets Curve." Ecological Economics 25, no 2: 147-160.

Wagner, M. 2005. "The carbon Kuznets curve: a cloudy picture emitted by bad econometrics?" Mimeo.

Welsch, H. 2004. "Corruption, growth and the environment: a cross-country analysis." Environment and Development Economics 9, no 5: 663-693.

World Bank, 2010. World Development Indicators 2010, available on line

Yandle, B., Bjattarai M., and Vijayaraghavan, M. 2004. "Environmental Kuznets Curves: A Review of Findings, Methods and Policy Implications." Research study 02.1 update, PERC. 
Table 1: Data information

\begin{tabular}{|c|c|c|}
\hline Variable & Definition & Source \\
\hline Y & Real per capita GDP & WDI (2010) \\
\hline Kpw & Capital Stock per worker & WDI (2010) \\
\hline$R$ & Rule of Law & Kaufmann (2010) \\
\hline Overallscore & Index of Economic Freedom & $\begin{array}{l}\text { Heritage Formation and } \\
\text { Wall Street Journal } \\
\text { (2010) }\end{array}$ \\
\hline Eurfrac & $\begin{array}{l}\text { Fraction of a country population that speaks one } \\
\text { of the five primary Western European languages, } \\
\text { including English as a mother tongue }\end{array}$ & Hall and Jones (1999) \\
\hline Engfrac & $\begin{array}{l}\text { Fraction of a country's population that speaks } \\
\text { English as a mother tongue }\end{array}$ & Hall and Jones (1999) \\
\hline$E D U$ & School enrolment, tertiary (\% gross) & WDI (2010) \\
\hline XIMint & Share of exports + imports in GDP & WDI (2010) \\
\hline $\mathrm{CO}$ & Per capita carbon monoxide emission & Eurostat (2010) \\
\hline COAL & $\begin{array}{l}\text { Percentage of electricity production from coal } \\
\text { sources }\end{array}$ & WDI (2010) \\
\hline MANUsh & Share of Manufacturing output in GDP & WDI (2010) \\
\hline Popdens & Population Density & WDI (2010) \\
\hline
\end{tabular}

Table 2: Summary Statistics

\begin{tabular}{lrrrrr}
\hline & Mean & Std. Dev. & Min & Max & Obs \\
\hline$Y$ & 24723.22 & 11987.3 & 5921.674 & 74421.63 & 363 \\
Kpw & 8459.583 & 5676.116 & 374.5925 & 32710.88 & 352 \\
$R$ & 1.148901 & 0.580172 & -0.193140 & 1.964045 & 364 \\
Overallscore & 66.15247 & 7.229807 & 45.7 & 82.6 & 364 \\
Eurfrac & 0.2444643 & 0.3945365 & 0 & 1.004 & 364 \\
Engfrac & 0.0612857 & 0.2234402 & 0 & 0.974 & 364 \\
EDU & 53.12494 & 18.25695 & 9.626324 & 94.88895 & 321 \\
XIMint & 105.6177 & 50.04793 & 44.15393 & 318.2252 & 362 \\
lnCO & -2.534302 & 0.3779758 & -4.087061 & -1.780269 & 308 \\
COAL & 3.020181 & 1.529222 & -3.865139 & 4.573292 & 279 \\
MANUsh & 18.72002 & 5.321808 & 7.463183 & 34.36443 & 326 \\
POPdens & 162.3201 & 231.2534 & 14.39792 & 1287.344 & 356 \\
\hline
\end{tabular}


Table 3: Estimation results for equation 5

\begin{tabular}{|c|c|c|c|}
\hline & G1 & $\mathrm{G} 2$ & G3 \\
\hline \multirow[t]{2}{*}{$R$} & $9,252.85$ & $-6,659.37$ & 993.273 \\
\hline & $(4,661.173)^{*}$ & $(2,121.705)^{* * *}$ & (1762.512) \\
\hline \multirow[t]{2}{*}{$K p w$} & 1.404 & 1.557 & 2.013 \\
\hline & $(0.137)^{* * *}$ & $(0.167)^{* * *}$ & $(0.234)^{* * *}$ \\
\hline \multirow[t]{2}{*}{$E d u$} & 34.469 & 34.651 & 52.179 \\
\hline & $(20.879)^{*}$ & $(25.81)$ & $(8.016)^{* * *}$ \\
\hline \multirow[t]{2}{*}{ XIMsh } & 52.481 & 43.318 & 36.532 \\
\hline & $(11.664)^{* * *}$ & $(11.905)^{* * *}$ & $(7.301)^{* * *}$ \\
\hline \multirow[t]{2}{*}{ Constant } & $-6,787.14$ & $13,409.26$ & -106.849 \\
\hline & $(7379.95)$ & $(2,288.912) * * *$ & $(1346.251)$ \\
\hline Obs & 119 & 70 & 122 \\
\hline N. of id & 11 & 7 & 10 \\
\hline $\mathrm{R}$-squared & 0.776 & 0.828 & 0.844 \\
\hline Wald $\chi^{\wedge} 2$ & 577.25 & 222.7 & 2242.27 \\
\hline Prob. & $(0.000)$ & $(0.000)$ & $(0.000)$ \\
\hline
\end{tabular}

Standard errors in parentheses

* significant at $10 \%$; * significant at $5 \%$; *** significant at $1 \%$

Table 4: First stage regression for equation 5

\begin{tabular}{lrrr}
\hline & $\mathrm{G} 1$ & $\mathrm{G} 2$ & $\mathrm{G} 3$ \\
\hline overallscore & 0.0069 & -0.00411 & 0.0094 \\
& $(0.003)^{* * *}$ & $(0.005)$ & $(0.003)^{* * *}$ \\
Eurfrac & -0.2466 & 0.424 & -4.854 \\
& $(0.053)^{* * *}$ & $(0.077)^{* * *}$ & $(8.340)$ \\
Engfrac & -0.0077 & 0.3562 & $\ldots$ \\
& $(0.086)$ & $(0.214)^{*}$ & $\ldots$ \\
Wald chi(6) & & & 69 \\
p-value & 40 & 90 & $(0.000)^{* * * *}$ \\
\hline
\end{tabular}


Table 5: Estimation results for equation 4 based on the models presented in table 3

\begin{tabular}{|c|c|c|c|c|c|}
\hline & $(\mathrm{Ya})$ & $(\mathrm{Yb})$ & $(\mathrm{Yc})$ & $(\mathrm{Yd})$ & $(\mathrm{Ye})$ \\
\hline \multirow[t]{2}{*}{$y g t$} & -0.000051 & -0.000107 & -0.000091 & -0.000068 & -0.000061 \\
\hline & $(0.000)^{* * *}$ & $(0.000)^{* * *}$ & $(0.000)^{* * *}$ & $(0.000)^{* * *}$ & $(0.000)^{* * *}$ \\
\hline \multirow[t]{2}{*}{$g t$} & 0.571 & 0.956 & 0.857 & 0.538 & 0.619 \\
\hline & $(0.140)^{* * *}$ & $(0.158) * * *$ & $(0.153)^{* * *}$ & $(0.165)^{* * *}$ & $(0.169)^{* * *}$ \\
\hline \multirow[t]{2}{*}{ RoLgt } & -0.919 & -0.392 & -0.412 & -0.441 & -0.498 \\
\hline & $(0.277)^{* * *}$ & $(0.254)^{* * *}$ & $(0.245)^{*}$ & $(0.238)^{*}$ & $(0.238)^{* *}$ \\
\hline \multirow[t]{2}{*}{$C O A L$} & & 0.0011 & -0.003 & -0.014 & -0.023 \\
\hline & & $(0.047)$ & $(0.046)$ & $(0.046)$ & $(0.046)$ \\
\hline \multirow[t]{2}{*}{$M A N U s h$} & & & 0.013 & 0.008 & 0.01 \\
\hline & & & $(0.004) * * *$ & $(0.004)^{*}$ & $(0.004)^{* *}$ \\
\hline \multirow[t]{2}{*}{ POPdens } & & & & -0.016 & -0.016 \\
\hline & & & & $(0.003)^{* * *}$ & $(0.003)^{* * *}$ \\
\hline \multirow[t]{2}{*}{ XIMsh } & & & & & -0.187 \\
\hline & & & & & $(0.099)^{*}$ \\
\hline \multirow[t]{2}{*}{ Constant } & 55.708 & 62.275 & 54.174 & 51.302 & 45.049 \\
\hline & $(4.869)^{* * *}$ & $(4.540)^{* * *}$ & $(5.058)^{* * *}$ & $(4.841)^{* * *}$ & $(5.841)^{* * *}$ \\
\hline Obs. & 286 & 244 & 235 & 229 & 229 \\
\hline N. of id & 26 & 23 & 23 & 22 & 22 \\
\hline $\mathrm{R}$-squared & 0.41 & 0.56 & 0.57 & 0.61 & 0.62 \\
\hline $\mathrm{F}-$ test & 60.21 & 68.32 & 55.39 & 53.24 & 46.73 \\
\hline Prob. & $(0.000)$ & $(0.000)$ & $(0.000)$ & $(0.000)$ & $(0.000)$ \\
\hline
\end{tabular}

Standard errors in parentheses

* significant at $10 \%$; * significant at $5 \%$; *** significant at $1 \%$ 